EUROPEAN JOURNAL OF ENVIRONMENT
European Journal of Environment and Public Health,

2018, 2(1), 04

ISSN: $2468-1997$

\title{
Awareness about Knowledge, Attitude and Practice of Medical Ethics pertaining to Patient Care, among Male and Female Physicians Working in a Public Sector Hospital of Karachi, Pakistan - A Cross-Sectional Survey
}

\author{
Sabeena Jalal ${ }^{1 *}$, Muhammad Imran ${ }^{2}$, Ashar Mashood ${ }^{3}$, Mustafa Younis ${ }^{4}$ \\ ${ }^{1}$ Babria University Medical and Dental College, Karachi, PAKISTAN \\ ${ }^{2}$ King Abdulaziz. University, Jeddah, SAUDI ARABIA \\ ${ }^{3} \mathrm{CMH}$ Peshawer, PAKISTAN \\ ${ }^{4}$ Jackson State University, Jackson, MS, USA
}

\section{*Corresponding Author: sjalalkhan@yahoo.com}

Citation: Jalal, S., Imran, M., Mashood, A. and Younis, M. (2018). Awareness about Knowledge, Attitude and Practice of Medical Ethics pertaining to Patient Care, among Male and Female Physicians Working in a Public Sector Hospital of Karachi, Pakistan - A Cross-Sectional Survey. European Journal of Environment and Public Health, 2(1), 04. https://doi.org/10.20897/ejeph/86260

Published: March 20, 2018

\begin{abstract}
The aim of the study is to assess the knowledge, attitudes and practices of medical ethics among male and female healthcare professionals in a public sector hospital in Karachi, Pakistan. A structured questionnaire about knowledge of medical ethics and its role in the everyday decision making in the hospital was developed, tested and distributed among residents, consultant physicians at the Abbasi Shaheed Hospital, a tertiary care teaching hospital, during June and August 2016. The paper analyzed 70 responses from doctors at various level of training comprising residents and consultants. Each question had sub parts and hence was scored accordingly. The participants encountered ethical decision making situations in a diverse regularity, varying from 'daily' to 'annually'. Interestingly, $9 \%$ of the doctors were not aware of the primary contents of the Hippocratic Oath, and $89 \%$ of these were junior doctors. Details of Nuremberg Code and Helsinki Code were known only to $4 \%$ of the total sample. Female physicians had a stronger opinion as compared to male physicians regarding practice of ethics. This included topics such as complying with the consent for procedures, treating violent/non-compliant patients, listening to the patient's wishes, autonomy and above all the attribute of maintaining confidentiality. A significant difference in the level of knowledge between diverse cadres of physicians was noted. Physicians who had cleared their qualifying and/or licensing exams exams in first attempt scored higher than those who did not. The female participants have 1.65 times the odds of having a higher knowledge about medical ethics, than male participants, keeping all other variables constant. The study highlights the need to strengthen the professional knowledge regarding medical ethics issues, among the health care workforce in public sector hospitals of the developing world. In our data, female physicians working in the government sector hospitals in Karachi, demonstrate a higher knowledge about medical ethics, than male participants, keeping all other variables constant.
\end{abstract}

Keywords: medical ethics, developing world, gender disparity

\section{INTRODUCTION}

Medical ethics is a field that demands attention as human life matters. In medical practice, the issues pertaining to medical ethics are often reflected as complaints about poor ethical conduct on the part of residents, fellows and consultant physicians. We also witness an increasing use of litigation against healthcare practitioners. Although 
ages ago Hippocratic Oath determined the significance of ethics as applied to medical practice. The Oath dates back to the ancient civilization. However, even today it is the guiding principle for moral musings and we see a symbolic adherence to the codes of conduct regulating the medical profession, which are reorganized from over time (Sauer, 1984). Dr. William Osler has laid great emphasis on ethics in his practice as a physician. The result of Dr. Osler's advocacy is that today, in many countries across the globe, medical ethics is a part of health professionals' training curriculum, and there has been a growth in the number of ethicists and ethical committees. However, despite this, complaints against healthcare professionals appear to proliferate. This perhaps could be due to inappropriate practices by the healthcare professionals compounded by increased public awareness (DuBois and Burkemper, 2002).

It is evident from literature, that traditional medical training does not offer much in resolving the ethical dilemmas, which are encountered as a matter of routine, by healthcare professionals. However, the practicing healthcare professionals are expected to possess sound knowledge about ethical practice (Hariharan et al., 2006; Miles et al., 1989).

Historically, there have been several reports emphasizing the significance of incorporating ethical issues into medical curricula (Green et al., 2000; Hanson, 2005; Roff and Preece, 2004). One study suggested simultaneous teaching of medical ethics to the residents, fellows and consultant doctors (Baldwin et al., 1996). Incidents of medical practitioners behaving unethically with patients as well as with their colleagues have been reported in literature. (Coulehan, 2005; Cowley, 2005; Baldwin et al., 1998). This creates room for reinforcing medical ethics training within the medical profession. Several recommendations have been put forward in order to strategize the teaching of medical ethics. After evaluating the current teaching programs, a significant body of literature emphasizes the importance of tailoring medical ethics curriculum according to the needs of the particular culture within a society (Hicks et al., 2001).

However, the teaching of medical ethics should ideally incorporate the cultural sensitivities and norms. Moral musing vary from society to society. Hence in order for the teaching to have an impact, the unique cultural, and socioeconomic background would have constructed it. Hence the curriculum of medical ethics should be tailored accordingly.

In order to formulate a medical ethics curriculum which is relevant to not just the country but also the setting within the country, we need to develop an understanding of the knowledge and attitude of the health care personal in the region. We simply cannot rely on pre established standards. After determining the general and targeted needs, we can direct the educational efforts to be better aligned to the national standards (D. S. Ethics, 1988). Only then can appropriate educational strategies be determined that are aligned to all aspects of the medical ethics curriculum, including the hidden curriculum. Even though the male and female physicians work together in providing care for their patients, however they may have differences with respect to their attitudes towards patientcare (Aarons, 2002). Given the above mentioned background, the present study is an attempt to elucidate the knowledge, attitude and practice of the various cadres of male and female physicians pertaining to healthcare ethics in public sector hospital in Pakistan.

\section{METHODS}

Ethics approval was obtained from the DERC of the medical unit, before conducting this study. Patient consent was not applicable. This study was a cross sectional survey of the medical staff. No patients were involved. Informed verbal consent was obtained from the participants of this survey.

The objective of this study was explained to each participant of this survey. Once they gave their verbal consent, their name was entered in a list (which was kept with the PI under lock and key) and a unique identifier was assigned of each questionnaire. Participants were explained that the results of the data analysis would be published. Data will be discarded after three years. After getting ethical approval, a pre coded questionnaire was used to gather data. A thirty item structured questionnaire, comprising of two parts, was administered among the residents, fellows and consultant physicians of the Abbasi Shaheed Hospital, Karachi, Pakistan. Questionnaire had 70 response options. The questions were designed to evaluate the knowledge of medical ethics in the public sector healthcare system in Karachi. The questionnaire was developed in English and then translated into native language and then back into English to see if the meanings of questions remained the same or not. Face and content validity were checked by piloting 10 questionnaires. The wordings of one question were changed and it was retested.

The recruitment in this pilot survey was done through convenience sampling. All residents, fellows and consultants working in Hospital, who had been working since at least one year, who gave verbal informed consent to be a part of this study, were included. Anonymity was maintained. The Abbasi Shaheed Hospital, is a 850 bedded, tertiary care teaching hospital located in one of the most populous neighborhoods in Karachi, it is also the third largest public sector hospital that comes under the umbrella of the City Government of Karachi. Pilot survey was conducted by using a pre coded questionnaire, during the months of July and August 2016. The 
questionnaire included a full range of response options, designed to identify the physician's knowledge, beliefs and attitudes towards patient care pertaining to medical ethics according to their professional cadre and to see whether gender disparity exists in the approach towards patient care.

Two part, pre coded questionnaires were used. First part of the questionnaire consisted of questions about the demographics such as occupation, age, gender, the duration of work experience, profession (resident, fellow and consultant doctors), whether they have been involved in any research project during last 5 years and the frequency of ethical problems encountered in practice. There were open ended questions, others had a choice of 'yes', 'no' or 'not sure' responses to pick from. Other were based on a scale of 1 (strongly disagree) to 5 (strongly agree). For questions with scale based answer options, respondents were asked to answer questions regarding everyday ethical issues that they face during their hospital work. Questions noted responses to matters concerning ethical conduct, autonomy, paternalism, confidentiality, informing patients about any mistake in treatment provided, relatives of patient knowing about the condition, informed consent, treating non-compliant or violent patient, religious beliefs influencing the choice of treatment.

Data were analyzed using STATA version 14.2 software. Descriptive analyses were done; the attitudes towards practical ethical problems were compared between residents, fellows and consultant physicians using a Chi square test. A Phi and Cramer's V value was obtained to determine the strength of the difference in their opinions. A p value of $\mathrm{p} \leq 0.05$ was considered as significant

Data was tested for normality. Log transformation was done for the continuous variables of age in years, years in service, years since graduation out of medical college, which were skewed in distribution. At univariate level, simple linear regression was applied. Outcome variable was the total score of each participant. Each variable was regressed independently with total score, their assumptions were checked, and their significance was reported. Gender was our primary exposure of interest. Variables that were significant on univariate regression were gender, age, professional designation, years of practice, whether they have been a part of any research project or not. They were selected for inclusion into multivariable linear regression analysis. We checked for multi-collinearity between independent variables and were assessed using a correlation coefficient. Cramer's V test was used for one nominal and one ordinal variable, Spearman test was used for one continuous variable and one ordinal variable. A correlation of 0.8 was treated as the presence of multi-collinearity. There was no multi-collinearity seen. Main effects were identified using step wise selection strategy and based on the p value; we decided to a keep a variable in the model or drop it. Though clearing a qualifying exam on first attempt was insignificant, yet we decided to keep the variable in the model as we wanted to see the impact of the variable in prediction equation. The multivariable analysis supported the inclusion of gender, age, whether they have been a part of any research project or not, academic rank in the preliminary model. The final step was to check for interaction. Interaction terms were created between each of the main effects in the model there were no significant interaction.

\section{RESULTS}

While conducting the survey, we found 255 participants who met the inclusion criteria of our study. However, 241 participants completed the questionnaire. 73 (30.29\%) were females and $168(69.71 \%)$ were males (Table 1). Majority of Residents, 85 out of 133 (63.91\%), 40 out of 56 Fellows (71.43\%) and 43 out of 52 Consultants $(82.69 \%)$ were males (Table 1, Figure 1). Our data revealed that out of the total $49(20.33 \%)$ of the overall doctors who cleared their fellowship exams in first attempt (Table 1). For the purpose of this study, fellowship exams was defined as MCPS part 1; MCPS part 2; FCPS part 1; FCPS part 2. Foreign exams were defined as MRCP part1; MRCP part 2; UAE/Gulf licensing exams; UK licensing exams; Canadian licensing exams; USMLE or any other medical licensing or qualifying exam. Each part/step of the foreign exam (whether licensing or qualifying) was considered a separate entity. $37(75.5 \%)$ had cleared their local qualifying exam in first attempt, whereas 12 $(24.49 \%)$ had cleared the foreign qualifying and/or licensing exam in first attempt. Among those who cleared in first attempt, $37(75.51 \%)$ were females whereas $12(24.49 \%)$ were males (Figure 2).

On matters concerning ethical conduct, out of the total score of 90 , the overall median scores were $75(0-88)$. For male residents, the median score were $75(0-88)$ for females it was $84(0-88)$. The median scores for female fellows was $80(0$ - 83), median scores for male fellows was $69(0-72)$. Among the male consultants, it was $62(3$ -74) and among female attending was $64(0-78)$. 
Table 1. Distribution of participants according to Gender

\begin{tabular}{llll}
\hline Variables & Males & Females & Total Available Numbers \\
\hline Total Numbers (\%) & & & \\
\hline Ranks (n=241) & $168(69.71 \%)$ & $73(30.29 \%)$ & $241(100 \%)$ \\
\hline Residents & $85(50.6 \%)$ & $48(65.75 \%)$ & $133(55.19 \%)$ \\
Fellows & $40(23.81 \%)$ & $16(21.92 \%)$ & $56(23.24 \%)$ \\
Consultants/Attending & $43(25.6 \%)$ & $9(12.33 \%)$ & $52(21.58 \%)$ \\
Total & $100 \%$ & $100 \%$ & $100 \%$ \\
\hline Local Exams & $9(24.3 \%)$ & $28(75.68 \%)$ & $37(100 \%)$ \\
\hline Foreign Exams & $3(25 \%)$ & $9(75 \%)$ & $12(100 \%)$ \\
\hline
\end{tabular}

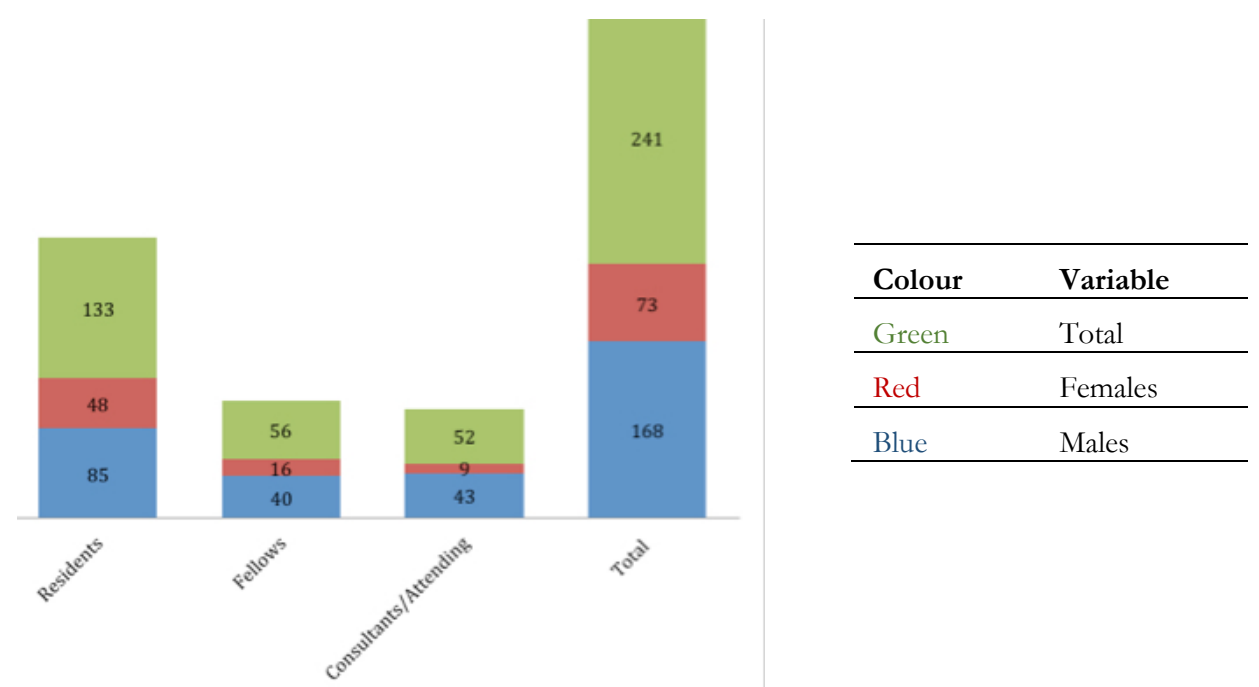

Figure 1. Distribution of participants by Ranks and Gender

Table 2. Association of academic hierarchy with gender and qualifying the exams in first attempt with gender

\begin{tabular}{cccccccc}
\hline \multicolumn{3}{c}{ Association of gender with rank $(\mathbf{n = 2 4 1 )}$} & \multicolumn{3}{c}{ Association of Gender with qualifying exam (n=49) } \\
\hline Male & Female & $\chi^{\mathbf{2}}$ & P value & Male & Female & $\boldsymbol{\chi}^{\mathbf{2}}$ & P value \\
\hline $168(69.71 \%)$ & $73(30.29 \%)$ & 6.34 & 0.042 & $12(24.49 \%)$ & $37(75.5 \%)$ & 0.00 .22 & 0.96 \\
\hline
\end{tabular}

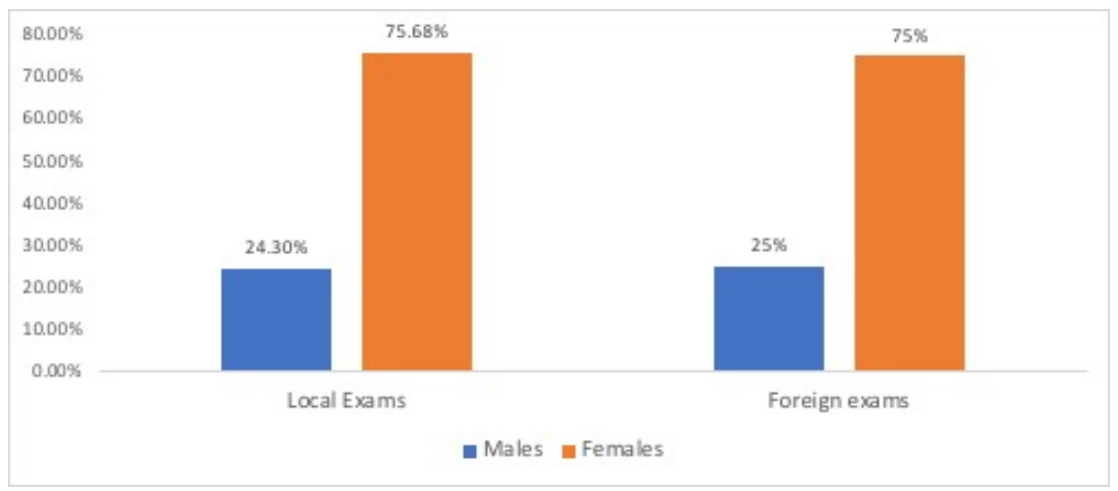

Figure 2. Distribution of Gender among those physicians who cleared their local or / and foreign qualifying exam in the first attempt.

In the bivariate analysis, chi-square was used to evaluate the association of gender with academic ranks (resident, fellow or consultant) and also whether they have cleared all levels of a qualifying and/or licensing exam in first attempt (Table 2).

There were a significantly greater number of males and females in the wards, $(\chi 2=6.34 ; \mathrm{p}$ value $=0.04)$. However, the difference became insignificant when we looked at gender distribution across qualifying exams. We also saw that there was a higher number of female residents as compared to female consultants. This shows a trend that more females are entering post graduation. 
Table 3. Median Score for Four departments/sections: two where a female was working in a leadership position and two where a male was working in a leadership position

\begin{tabular}{lccccc}
\hline Leadership position & \% Males & \% Females & $\begin{array}{c}\text { Patient's autonomy } \\
\text { (Total Score= 50) }\end{array}$ & $\begin{array}{c}\text { Consent } \\
\text { (Total Score= 18) }\end{array}$ & $\begin{array}{c}\text { Confidentiality } \\
\text { (Total Score= 85) }\end{array}$ \\
\hline Female & 60 & 40 & $21(12-49)$ & $7(5-15)$ & $62(27-83)$ \\
\hline \multirow{2}{*}{ Male } & 68 & 32 & $32.5(10-44)$ & $10(8-16)$ & $60.2(24-79)$ \\
\cline { 2 - 6 } & 62.5 & 37.5 & $25.5(12-40)$ & $5(4-7)$ & $8(7-14)$ \\
\hline
\end{tabular}

The female percentage is higher at junior ranks of profession, as that of residents. However, we see that this trend changes, as a greater percentage of males are becoming consultants. Among females, 28 participants had cleared their qualifying exams in first attempt. 23 had cleared the local exam and 5 had cleared their foreign exam in first attempt. Among males, only 9 faculty members had cleared their qualifying exam in first attempt. Among them, 6 had cleared the local exam and 3 had cleared the foreign exam in first attempt (Table 1).

\section{The Model}

$\hat{y}($ Score $)=3.15+\beta 1($ Gender $)+\beta 2($ Age $)+\beta 3$ (Fellow $)+\beta 4$ (Resident $)+\beta 5$ (Prior Research $)+\beta 6($ Cleared qualifying exam in first attempt)

This prediction equation accounted for major variability in the model as adjusted $\mathrm{R}$ square $=0.929$, $\mathrm{F}$ test was 53 , $\mathrm{p}$ value was $\leq 0.001$. The remaining variability in the model may have been explained by variables such full time versus part time employment; years of employment and contract versus tenure positions. However, this was beyond the scope of our paper, the female doctors of Abbasi Shaheed Hospital have 1.52 times the odds of having a higher score than males faculty, keeping all other variables constant.

In order to observe whether a female leadership enhances the female faculty numbers, we looked crosssectionally at four departments/sections. Departments were chosen randomly. Permission was obtained by the respective heads of the departments. A similar pre-coded questionnaire was used. We compared the participants of these departments based on the responses on three areas: Autonomy (total score $=50)$, Consent (total score $=18$ ) and Confidentiality (total score=85). Among these four departments/sections, a female faculty was in a leadership position (either head or a professor) in two departments. We noted that even though male faculty was still in majority numbers even in those departments which had a female leader, yet the male to female faculty ratio had improved as compared to the overall M:F ratio (Table 3). The departments/sections, headed by a female had a comparable score $(\mathrm{p}$ value $=0.06)$ when compared to the overall median score $($ Table 3$)$. We did see visible trend of female faculty progression in the departments/section where a female was serving in a leadership position. Whether the credit goes to the female faculty or the overall administration, is another area that could perhaps be explored in future.

Gender was our primary exposure of interest. Variables that were significant on univariate regression were gender, age, professional designation, years of practice, whether they have been a part of any research project or not. They were selected for inclusion into multivariable linear regression analysis. The multivariable analysis supported the inclusion of gender, years of professional practice, whether they had conducted research or not and post graduation in the preliminary model. The final step was to check for interaction. Interaction terms were created between each of the main effects in the model there were no significant interaction.

Work experience ranged from 1 year to over 28 years. $35(\approx 95 \%)$ of resident physicians were in the age group of $20-29$ years and $26(\approx 72 \%)$ of them had $4-10$ year work experience. $33(\approx 77 \%)$ of fellows were in the age group of 30-49 years and $67 \%$ of them had work experience of $7-20$ years. $7(\approx 80 \%)$ of consultant physicians had been working since at least 10 years.

When asked whether the practice of medical ethics is of any significance to the profession of health and allied sciences, particularly the field of medicine, all the consultants and resident physicians and $94 \%$ of fellows agreed.

$64 \%$ of the respondents answered that they acquired their knowledge of ethics from multiple sources, such as seniors, colleagues and Continuing Medical education (CME) lectures, medical journals and newspapers. A high number, that is, $62 \%$ of physicians responded that they acquired their knowledge of medical ethics while working in the hospital and while dealing with a diverse array of situations.

Among the $9(\approx 19 \%)$ of physicians who were unaware of the main components of the Hippocratic Oath, there were 8 residents, one consultant physician. Also noteworthy is the fact that a significant number, that is, $96 \%$ of physicians were unaware of the details of Nuremberg Code or the Helsinki Declaration. 


\section{The Model}

$\hat{y}_{\mathrm{y}}$ (Score) $=\beta 0+\beta 1($ Female $)+\beta 2($ Years of practice $)+\beta 3($ Post graduation $)+\beta 4($ Conducted research $)$

This prediction equation accounted for major variability in the model as adjusted $\mathrm{R}$ square $=0.88, \mathrm{~F}$ test was 741.2 , $\mathrm{p}$ value was $\leq 0.001$. The remaining variability in the model may have been explained by variables such full time versus part time employment and contract versus tenure positions. However, this was beyond the scope of our paper, the female participants have 1.65 times the odds of having a higher score than males participants, keeping all other variables constant.

\section{DISCUSSION}

The findings of this study does not show a significant difference in the knowledge and attitudes of physicians working in the public sector hospital, regarding the issues pertaining to medical ethics. The participants of this study were from different strata of seniority among physicians. They consisted of residents, fellows and consultant physicians employed in a public sector hospital, in the developing country.

The results of this study report the frequency of encountering ethical problems ranging from "never" to "every day". Junior physicians stated that they encountered ethical dilemmas more often in their practice as compared to the consultant physicians. One explanation for this situation could be that the front line doctors have a more frequent interaction with patients. This perhaps results in the problem being resolved at the junior level and due to the lack of proper incident reporting system, the consultant physician never learns about the issue (Fox and Arnold, 2005). However, this highlights the need for a system in place which enables reporting and recording such issues. It should also be mentioned how such problem were addressed.

Most of the study participants agreed to the importance of medical ethics. Among those who had marked that the knowledge of ethics was not an important issue, they had also marked that they never came across situations that needed such consideration. One explanation for such a situation could be that these participants were ignorant regarding knowledge of ethics, and therefore were unable to identify them when they faced such situations in their practice.

It is interesting to note that academic training was reported be to be less impactful as the source of knowledge of healthcare ethics amongst residents, than their experience of working at the hospital. The other sources that they stated were the lectures and seminars that they attended as junior physicians and by reading medical journal articles (DuBois and Burkemper, 2002). No one picked a single source as a tool for learning medical ethics. Eight junior doctors reported that they looked through published literature as a guide in solving the ethical matter that they had encountered in the practice. Many of the respondents preferred to consult their colleague, immediate supervisor or the head of their department for ethical issues. The fact that majority of the participants of this study, that is, more than $90 \%$ of the respondents had no knowledge regarding the Nuremberg Code and or the Helsinki Declaration, indicates that there is very little knowledge regarding the ethics of research. This demonstrates that there is a void in the structure of curricular training regarding medical ethics and that can be improved upon. Literature reports that traditionally, healthcare personnel receive limited training in formal ethics, even though their daily work involves direct and often crucial intervention in others' lives (Coulehan, 2005; Reynolds, 1991; Reynolds, 1994; Angelos et al, 1999). Since all cadres of physicians feel that their main source of knowledge of medical ethics was during experience at work, this could be taken as an opportunity to reinforce their ethical knowledge and practice. Teaching in the ward could involve video lecture, small group discussions and even focus group discussions.

This study noted that answers from physicians to queries regarding medical ethics advocate that the bulk of them were mindful of the most widely prevalent ethical issues. Residents and consultants were noted to have significantly stronger opinions about the different medical ethics issues as compared to the fellows. For instance, in certain issues such as adherence to patients' wishes, confidentiality, paternalistic attitude of doctors, consent for procedures and treating violent patient or a non-compliant patient, the doctors marked "strongly" more often than fellows. This may reflect the difference in the training between the two professionals. Perhaps fellows are trained to be in a supportive role to the doctor in some setting. However, there may also be regional variations in attitude towards patient's autonomy (Hariharan et al., 2006; Dickenson, 1999; Sulmasy et al., 1995). Our study shows that female physicians had a 1.65 times the odd of scoring higher than male counter parts when tested for medical ethics knowledge when adjusting for other variables. Health care professional who had been involved in research and who had cleared a qualifying exam in first attempt, showed a higher level of knowledge regarding medical ethics. 


\section{LIMITATIONS}

This study was a single center study, hence results cannot be generalized.

\section{CONCLUSION}

Ethical conflicts are common in the everyday decisions of residents, fellows and consultants. Nevertheless, several of these professionals are either uninformed of the significance or simply cannot manage the ethical issues that they come across in their everyday practice at the public sector hospital in the developing world. The reported findings of the study identify that fellows perspectives regarding professionalism and ethics need to be improved. Practical education in ethics, particularly in a multidisciplinary setting, could assist in improving the knowledge, attitude and practice pertaining to ethical approach. Such activities will help us formulate educational approaches that will fulfill our responsibilities as medical educationists in preparing the next generation of physicians to function with improved ethical competence. Dignity for all patients is much needed in the developing world. Our study also noted that the female participants have 1.65 times the odds of having a higher score than male participants, keeping all other variables constant. Reasons for this disparity need to be explored in further multi center studies

\section{REFERENCES}

Aarons, D. (2002). Issues in bioethics. Teaching medical ethics to health professionals. The West Indian Medical Journal, 51(2), 59-63.

Angelos, P., DaRosa, D. A., Derossis, A. M. and Kim, B. (1999). Medical ethics curriculum for surgical residents: results of a pilot project. Surgery, 126(4), 701-707. https://doi.org/10.1016/S0039-6060(99)70125-X

Baldwin, Jr. D., Daugherty, S. R., Rowley, B. D. and Schwarz, M. (1996). Cheating in medical school: a survey of second-year students at 31 schools. Academic Medicine, 71(3), 267-273. https://doi.org/10.1097/00001888199603000-00020

Baldwin, Jr. D., Daugherty, S. R. and Rowley, B. D. (1998). Unethical and unprofessional conduct observed by residents during their first year of training. Academic Medicine, 73(11), 1195-1200. https://doi.org/10.1097/00001888-199811000-00019

Coulehan, J. (2005). Viewpoint: Today's Professionalism: Engaging the Mind but Not the Heart. Academic Medicine, 80(10), 892-8. https:/ / doi.org/10.1097/00001888-200510000-00004

Cowley, C. (2005). The dangers of medical ethics. Journal of Medical Ethics, 31(12), 739-742.

D. S. Ethics: The heart of health care. (1988).

Dickenson, D. L. (1999). Practitioners' attitudes towards ethical issues at the end of life: Is the UK actually more autonomy-minded than the US? Journal of Palliative Care, 15(4), 57.

DuBois, J. M. and Burkemper, J. (2002). Ethics education in US medical schools: a study of syllabi. Academic Medicine, 77(5), 432-437. https://doi.org/10.1136/jme.2005.011908

Fox, E., Arnold, R. M. and Brody, B. (1995). Medical ethics education: past, present, and future. Academic Medicine, 70(9), 761-768. https:// doi.org/10.1097/00001888-199509000-00013

Green, M. J., Farber, N. J., Ubel, P. A., Mauger, D. T., Aboff, B. M., Sosman, J. M., et al. (2000). Lying to each other: when internal medicine residents use deception with their colleagues. Archives of Internal Medicine, 160(15), 2317-2323. https://doi.org/10.1001/archinte.160.15.2317

Hanson, S. (2005). Teaching health care ethics: why we should teach nursing and medical students together. Nursing Ethics, 12(2), 167-176. https://doi.org/10.1191/0969733005ne773oa

Hariharan, S., Jonnalagadda, R., Walrond, E. and Moseley, H. (2006). Knowledge, attitudes and practice of healthcare ethics and law among doctors and nurses in Barbados. BMC Medical Ethics, 7(1), 1. https://doi.org/10.1186/1472-6939-7-7

Hicks, L. K., Lin, Y., Robertson, D. W., Robinson, D. L. and Woodrow, S. I. (2001). Understanding the clinical dilemmas that shape medical students' ethical development: questionnaire survey and focus group study. Bmj, 322(7288), 709-710. https://doi.org/10.1136/bmj.322.7288.709

Miles, S. H., Lane, L. W., Bickel, J., Walker, R. M. and Cassel, C. K. (1989). Medical ethics education: coming of age. Academic Medicine, 64(12), 705-714. https://doi.org/10.1097/00001888-198912000-00004

Reynolds, P. P. (1991). Professionalism in residency. Annals of Internal Medicine, 114(1), 91-92. https://doi.org/10.7326/0003-4819-114-1-91

Reynolds, P. P. (1994). Reaffirming professionalism through the education community. Annals of Internal Medicine, 120(7), 609-614. https://doi.org/10.7326/0003-4819-120-7-199404010-00013 
Roff, S. and Preece, P. (2004). Helping medical students to find their moral compasses: ethics teaching for second and third year undergraduates. Journal of Medical Ethics, 30(5), 487-489. https://doi.org/10.1136/jme.2003.003483

Sauer, Jr. J. (1984). Ethical problems facing the healthcare industry. Hospital \& Health Services Administration, 30(5), 44-53.

Sulmasy, D. P., Dwyer, M. and Marx, E. (1995). Knowledge, confidence, and attitudes regarding medical ethics: how do faculty and housestaff compare? Academic Medicine, 70(11), $1038-1040$. https://doi.org/10.1097/00001888-199511000-00024 